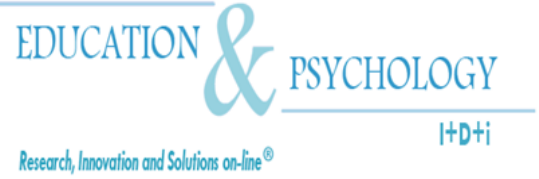

\title{
Diverse learning episodes: naturalistic observation in an early mathematics classroom
}

\author{
Michalis P. Michaelides
}

School of Humanities \& Social Sciences, European University Cyprus, Nicosia

\section{Cyprus}




\begin{abstract}
This applied paper is a report of a naturalistic observation in a mathematics classroom focusing on two second-graders. Following an exploratory visit to understand the setting and develop more specific questions for the study, the purpose of this empirical investigation was to describe the behavior of two children in the particular classroom setting. The two children expressed different patterns of reactions while working on individual activities and in whole class instruction. Field notes on the students' behavior and the classroom environment were collected during visits. Evidence on the strategies the two children used was also recorded. Accounts from the collected observations are briefly presented and interpreted. Conclusions are drawn and further questions are raised.
\end{abstract}

Keywords: naturalistic observation, mathematical behavior, classroom setting, interpretation of episodes

Received: 02/01/09 Initial Acceptance: 04/02/09 Final Acceptance: 03/23/09

\title{
Resumen
}

El artículo presenta un informe de observación natural en el aula de matemáticas centrado en dos alumnos. Tras una exploración inicial para comprender el contexto y desarrollar cuestiones más específicas para el estudio, el objetivo de esta investigación empírica fue describir el comportamiento de dos niños en una situación de clase específica. Los dos niños mostraron diferentes patrones de actuación tanto trabajando en actividades individuales como grupales. Durante las visitas realizadas se recogieron notas de campo sobre los comportamientos de los estudantes y el clima de aula. Además se grabaron las estrategias utilizadas por ambos niños. Presentamos de forma breve los resultados de las observaciones realizadas y se realiza la interpretación de los mismos. Por último, se establecen las conclusiones y nuevos interrogantes.

Palabras clave: observación natural, comportamiento matemático, aula, interpretación de episodios.

Recibido: 01/02/09 Aceptación inicial: 04/02/09 Aceptación final: 23/03/09 


\section{Introduction}

Naturalistic observation, an observational approach carried out in the natural environment of the participants is a method commonly used in the study of child development. This report is an attempt to apply systematic observation in the context of a small exploratory research study, involving two children in a second-grade, mathematics classroom.

In this paper, I state first the guiding questions and the process through which they were generated. Then I provide a brief portrayal of the school and the classroom setting, as well as the methodology employed to answer the research questions. A more detailed presentation of the observations of the classroom and of the two individual children is given, each followed by a commentary and an analysis. Finally, conclusions are summarized and further questions are raised.

\section{Developing Guiding Questions}

The first classroom visit to observe a mathematics lesson was essentially exploratory. The aim of this visit was to choose a specific research question to guide further observations for a small-scale, empirical study. My first impression was that the environment of the classroom and the activities that the teacher had chosen, engaged all the children in the tasks. Most of the time was devoted - but not limited to - the practice of basic addition and subtraction up to one hundred in original activities, which kept the children's interest at high levels. Other activities touched on multiplication, measurement, estimation, graphs. In some cases children were surprisingly fast in their responses to the teacher's questions!

I had noticed two children who in certain ways were not typical. Marc made himself noticeable right away: commenting on everything out loud, not following the instructions immediately as they were given, often not paying attention, but nevertheless able to follow the activities, participate in whole class instruction and respond correctly. The second was Christina, a quiet and attentive girl, not so eager to talk in front of the whole class, but who was usually successful in the tasks she completed and the questions she answered.

These two children provided two distinct kinds of behavior in the classroom. I was interested in seeing how two children who behaved differently in front of the class approached 
individual tasks and whole class instruction; in other words, I wanted to see whether they were engaged, and interested in the tasks, or not, and how this behavior was manifested in each case. I wanted to see if there was a relationship between that behavior and the practices that the teacher used to employ, and the classroom climate, in general. A second more ambitious idea was to explore characteristics of strategies they used during their participation in the activities; mental strategies that would possibly be directly observable or at least inferred by their actions seemed to be a question I could pursue in the observation sessions that would follow.

\section{The setting and the methods}

The school where the observations took place is in a rural, but prosperous community in northern California. The population is predominantly white, and of high socio-economic status. The principal and the staff were very helpful during my visits to the school. At the first visit, when I asked for a mathematics class in an early grade for an observational study, a particular second grade was suggested.

I had the chance to talk and listen to the teacher of that second grade before class started. The teacher assistant was absent on that first day, but was present in my next visits. Her class was full of visual stimuli, mostly having to do with numbers. The walls were covered with pictures, charts, posters, a number line, and materials that were apparently used frequently for everyday activities. There were also "corners" for various learning activities, such as weighting, playing with toys, practicing on computers. There were five computers in total. Too many materials were "pilled up" in some places, like the teacher's desk, but nobody seemed to bother with the untidiness. A diagram of the classroom can be seen in Figure 1.

The methodology followed in this study was direct observation, during which according to Wright (1960) “(1) [n]o planned arrangements stand between the observer and his target phenomena, and (2) neither does appreciable time: recording closely follows observing" (p.71). I positioned myself in places where I had direct contact with the children I wanted to observe, and I recorded direct observation notes (Neuman, 2006) spontaneously.

The first visit was made just before the Easter break. Since it was of an investigative nature, the observations referred to the classroom activities in general. After the Easter break, 
having the guiding questions in mind, the observation sessions were more goal-oriented. As regards methodology, time sampling was used. I observed and noted behavior in predetermined time intervals, to obtain "representative time samples of the target phenomena" (Wright, 1960, p.93). Ten-minute intervals were arbitrarily chosen and I exchanged my focus from one child to the other every ten minutes during periods of mathematics. In total I observed each child for four ten-minute time samples.

I wrote down brief descriptions of observed behaviors, their duration and sometimes some accompanying comments. Of interest were the teacher's instructions and the task that the student was supposed to carry out. For convenience some typical behaviors were precodified, although eventually they were not very helpful. Free-form, spontaneous field notes were more useful. The coding sheet was also divided in half-minute "boxes" to help keep track of time. A diagram of the classroom and sketches of some of the materials were created to assist interpretations following the data collection (Cohen, Manion, \& Morrison, 2000; Neuman, 2006).

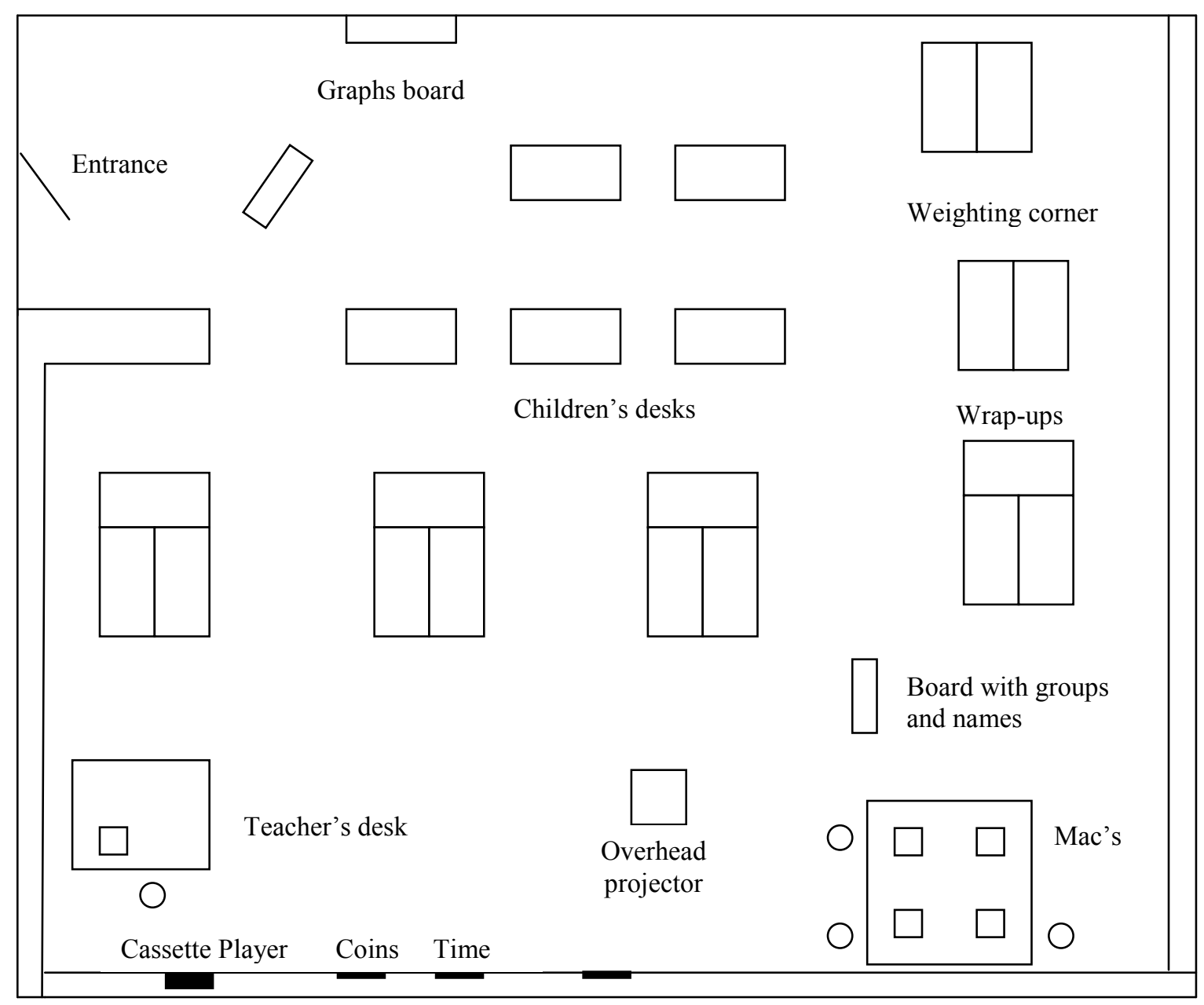

Figure 1. Classroom layout 


\section{Observation episodes and analysis}

\section{Exploratory observations during the first visit}

The children walk with their teacher to the classroom. Before entering, they stand in line and listen to the instructions for the first activity. As soon as they enter, they place individual magnets with their names on, in one of the groups on the graph board, as an answer to the question "What's your favorite dip?" They choose between lake, ocean, creek and pool. They move to the front of the classroom next to the teacher's desk and sit on the floor. The teacher notes down which children are absent. Using a poster numbered with all the days of the year and with colored patterns, the teacher asks what day is it since the beginning of the year and how many are left until recess, as well as patterns with previous days. Two children are asked simultaneously to show a particular time on a clock and an amount of money with coins stack on a poster. Two more children repeat the same tasks. The teacher checks her email, while the children pick up their white erasable boards on which many start writing or drawing with markers. The whole class then counts one-by-one the coins that form different combinations of amounts.

Tape listening is the next activity. "Make a plus six," says the teacher and plays a cassette with music during which numbers (range 0-10) are heard arbitrarily approximately every five seconds. The children are supposed to write down the sum of each number with six on their boards. Some children are not fast enough to get all the sums; some because do not pay attention from the beginning and others because thinking a sum takes more time than the tape interval. For instance, both of these happened with Marc who was called by the teacher to stop disturbing a fellow classmate and concentrate on the task. Answers are checked. The same activity is repeated with the question "What's the difference of this number (i.e. number heard from the tape) with 12?" Many children don't get most of the answers. Next questions are "Double the number" and "Double-double (i.e. times four) the number", the former being easy in general, the latter being more difficult. The teacher then answers a telephone call.

The children are asked to put their boards back to their place, return in the front of the room and form two groups. The transition is not quiet. The teacher calls Marc for teasing a classmate and says that he will be sent to the principal if he continues. Eventually he is sent back to his desk. The teacher explains a poster with hidden numbers and their sums. A child 
from each group is asked to reveal two spots on the poster. If the two spots match two numbers with their sum (e.g. $7+5$ and 12) the group wins a point. All children get a try either by guessing or using their memory.

The children return to their desks and the teacher moves to the overhead projector, where she spreads plastic ants. She projects them for a few seconds and then asks for an estimate. She notes down the range. New projection of the ants and children give new estimates having been asked to aim for a narrower range. The process is repeated twice after the teacher forms four and then six groups of five ants. The purpose of the grouping strategy to enable a more precise estimation is explained.

The class turns to the graph board at the back of the classroom. The teacher asks questions about the relative numbers of names in each kind of "dip". Then presents some pots and asks each child to pour some colored liquid with a big "spoon" from a big vase into the pot that corresponds to his/her preferred "dip". When they finish, she asks comparison questions about the four pots-"dips". The "volume graph" is also compared to the original "magnetic name graph" on the board. Finally, the children mention who would probably find such information useful and justify their proposals. After that, the children spread into groups and move to different activities, e.g. two play "math storm" on the computers, two move to the weighting corner to measure the weight of certain objects written on a sheet, seven children play "froggies", a table game, etc.

\section{Commentary on the first visit}

The organization of the classroom and some typical "codes of conduct" facilitated the functioning of the classroom and the activities were efficient and productive. The children seemed to know some procedural rules, the every-day routines, so moving around in class as they changed between activities did not cause much trouble. The teacher gave only minimal, but sufficient instructions to the students to find out where they should move and what to do. In fact, they were familiar with most of the activities, because they had probably not been new for them. Particularly, for most of the activities that were not addressed towards the whole classroom, the teacher did not attend to at all. Nevertheless, the children knew what the goal was and what was expected from them to do. 
Most of the tasks revolved around the skills of addition and subtraction. Occasionally, these skills were expanded to include bigger numbers, or more complicated operations. The increasing difficulty in the double-double operation was an informal introduction to the notion of multiplication as a repeated addition, i.e. $4 \times 6=6+6+6+6$. Other concepts in completely different units were introduced, or revisited, as well. The continuous exchange between topics, together with the originality of the activities, which in these topics are usually approached in mechanistic, "drill and practice" exercises, kept the children focused on task. Typically, children are bored when they have to make a series of sums including a specific number; with the use of the tape however, the limited time intervals of the speaker and the background music, they concentrated and put serious effort in an otherwise tedious activity.

A couple of more characteristics made the lesson exciting. One is the plentiful use of educational media: cassette player, overhead projector, and computer software; the use of a variety of posters on which children could act and not just observe, real-world objects, such as coins and scales, music and colored liquid, educational toys and team cooperation in competitive games made the activities attractive. The second is the general "flow" of the lesson: the fast pace, the exchangeability between activities, the transitions, the informal character of interaction - sitting on the floor, movements, the teacher checking her email, or answering the telephone - the simultaneous operation on different tasks by different groups of students, excluded the picture of a rigid, strict classroom. Although there were some explicit, or implicit rules, the impression to an external observer, and presumably to the children, was one of mobility, variation, freedom and choice.

\section{Focus on Marc: Four episodes observed}

(a) It is the beginning of the day. Marc has entered the class with the rest of the children, but unlike those who go and sit at the front of the class, he is standing at the end of the group. He leaves the group and goes back to the graph board where he had already put his name on. He soon returns back, approaches the teacher and says something to her. He listens for few seconds to the ongoing "warm-up" activity of counting and finding patterns with days. He soon gets distracted and plays with a book, while going to sit far from the other children. The teacher calls him after the activity has finished to move the board next to him, and use a pointer to point at words of a song written on that board. He gets the pointer and asks for clarification about what to do. The song is about the number nine. The teacher plays a tape with the song and he is listening carefully, while at the same time reading the verses on 
the board. He looks very serious. Occasionally, he whispers the words. The teacher replays the song and asks him to point at words at the rhyme and the other children to sing. He is looking carefully at the board and tries to point at words at the right pace. The song is played once more; Marc misses the beginning, but soon finds the rhyme. He is not singing like the rest of the class; only points at the board.

(b) The children are in individual and group activities and the teacher calls for clean up and gathering for a whole-class discussion of the graph. Marc stays at his desk. The other children form four groups according to gender and birthday season (fall-winter or springsummer) but Marc ignores them, looks absent-minded sitting at his desk. A minute later he says, “Oh, I'm in winter!" and goes to join his group. The teacher asks them to sit on the floor and Marc does that like the rest. She forms a histogram on the board by asking questions about the groups. Without being asked, Marc says loudly that he has noticed a pattern in the graph and seen it before. He listens to some more questions and responses by his classmates. To the question "Do you notice a pattern in the graph?" he raises his hand. He is picked up after a few wrong responses, but he says something wrong as well, and the teacher moves to another response. He still raises his hand while others attempt to answer the question. He listens to the short conversation that follows but does not participate.

(c) Marc is sitting on his desk with the activity sheet on measurement. He asks the teacher assistant for help, how to measure the objects he has to measure. He moves away from his desk looking for a pencil. A minute later he uses a "thumb-ruler", a paper with drawings of thumbs as measures on it, to measure parts of his face after giving an estimate first. He writes the results down. Then, he talks to the boy at the next desk. Having to measure the length of a hair, he spends about a minute trying to take a hair off. He laughs and comments about it with the other boy. When he gets one, he wonders "How wide is the hair?" looking puzzled. Marc tries to measure the width of the hair. Moving to the next measurement, he asks the teacher assistant for a marble. When he gets one, he throws it and estimates how far it went. He says "28!" and writes it down both as an estimate and as a measurement. He then reads emphatically "How wide is the room?" Then responds to himself "I'm not doing that!" and goes to get a new activity. The teacher assistant says that he has to do it and he returns back to his desk talking to himself.

(d) Marc is sitting alone at his desk at the back of the class. He has paper sheets in front of him but he is playing with his hands and the animals drawn on his hands for about 
two minutes. He comes back to the task and measures parts his hands with a tape measure. He says the answers to himself outloud and gets excited. While doing that he repeats phrases he hears from his classmates to tease them without interrupting what he is doing. He then says, "How wide is the room?... I have to walk that way..." He walks across the class while putting his thumbs next to each other in the air and counts the width in thumbs. He finds 58 and writes that down. But he notices with surprise "This is less than the desk!... I have to do something else... I need more rulers". He stands up and looks for more thumb-rulers to measure, while talking to himself. He asks the teaching assistant and borrows one. He measures the width of the desk by putting his thumbs next to each other and counts. The girl on the next desks says "No, that's not the way" and he starts again by putting both thumbs together and counting by two. He finds 48 thumbs.

\section{Comments and analysis on Marc's observation}

Marc was one of the noticeable children in the classroom; he is not quiet, makes comments outloud about anything going on in the class, does not easily conform with instructions, occasionally causes trouble, but despite that, he is able to follow the activities in the classroom, respond to assignments and have an opinion for everything.

What could be said about Marc is that he is not easy with instructions, in general, especially those that are addressed to the whole class and everybody should follow. So, for example he does not sit when everybody is sitting, or says "I'm not doing that!" and puts an end to his task - however he will return back to it when the teacher assistant suggests so, or he will conform and be quiet when for example the teacher warned him that he was going to be sent to the principal, or back to his desk. He accepted though, rather with satisfaction, the role of pointing to the lyrics of the song when all the rest were supposed to sing. Considering also that he did carry out the individual activities he had been assigned, as well as the fact that his desk was at the end of the classroom and that he was sitting there alone, some speculations can be made about his behavior and his relationships with the teacher and the rest of the class. He does not concentrate on a task easily and right away; he questions the rules and gets easily distracted. Group activities do not seem to be very interesting to him, but he prefers roles where he can perform alone and be distinct from his classmates. The teacher has probably noticed the diverse characteristics of Marc and responds in certain ways that could be, either warning and punishment, or assignment of special tasks. Whether working alone on the activ- 
ities and not as a part of a small group was intentional - as part of an "informal and silent mutual deal" between teacher and Marc - or not cannot be answered because of the limited observation time. It seems likely however that both of them are comfortable with such assignments. It would be interesting to see how Marc reacts when working in a small group. If a prediction could be made about that case, I would tentatively say that Marc would certainly get involved in the activity, express opinions strongly, suggest possible actions, criticize other suggestions, but not get to do what he wants; I think that the rest of the children would ignore most of his suggestions.

Although he is reluctant to conform with the rules and difficult to stay focused on a task, Marc's performance as regards getting the right answers in the practice exercises, completing his activities and responding to questions is very good. He tends to engage in more than one action at the same time and presumably gets often destructed, but he often manages to return on task and continue his endeavor. In his individual writing tasks on measurement, I could actually listen to his thinking aloud processes. After reading the task aloud, he seemed to "negotiate" with himself about what procedure to follow, or comment on the difficulty, decide about a solution, or even repeat ironically a classmate's words - without removing his focus from the paper and immediately coming back to the task. He was in a kind of collaboration with himself. This strategy was in some cases successful as he talked out possible solutions he could subsequently pursue and at other times detect problems and errors in his previous reasoning. However, the effort to understand the thinking processes and the strategies used through observation alone is not typically fruitful, because the observer depends on the observable behavior only. In Marc's case, much of the thinking was expressed orally and with the related intonation, but even so it is not enough to form a detailed idea about thinking strategies; moreover, voluntary expressiveness of reasoning is rarely the case in children.

\section{Focus on Christina: Four episodes observed}

(a) All the children are sitting at the front of the class on the floor. Christina is quiet and listens to instructions from the teacher. When told that they are going to work in groups and have to find out the newly formed groups that are written on a moving board, she gets up, moves towards the board and finds out her name and group. Returns back and sits on the floor again. She looks sleepy as she listens to more instructions about group activities. The girl next to her whispers something to her. She responds back. She is then staring at another girl. She says something to her before turning back to the teacher. She shows to the girl next 
to her a wound on her knee and describes how she got that. She gets up and moves to the back of the classroom. After thinking for a few seconds, she goes back to her desk and picks up a pencil and a sheet of paper. She returns to the activity corner and prepares her paper: she draws a table. She talks to the girl who is going to work on the same activity about the table she drew and what she is going to do first.

(b) The class is sitting on the floor at the back of the room. A problem about the graph was posed and Christina is raising her hand. She looks absent minded. Lowers her hand, gets distracted by looking at a classmate. The teacher says, "Go back to the rug". Christina gets up and grabs another girl's hand as they walk to the front of the classroom. She plays with two other girls on the way. She sits on the floor very close, in front of the teacher and listens to her instructions about the song about zero they are going to listen to and make certain movements. The song starts and Christina, like other children, points to different directions according to the lyrics. The song is interrupted because someone is making noise and disturbs others. The teacher asks them to stand up and gives instructions for certain movements during the next song about place value. Song starts and like everyone else, she makes the movements according to the song. She sings loudly at the point of "ones-tens-hundreds" when the "important" movements need to be made. She looks excited, as the activity is repeated for almost three minutes. "Back to your desks", says the teacher and Christina goes back to her desk quickly.

(c) Christina is in the "wrap-ups" corner. She has already done three "wrap-ups" (see Figure 2 for a sketch of a "wrap-up" and a description of how it works) as can be seen on the report paper she has in front of her. She is working silently on a " +3 ". She is wrapping the thread around the plastic part quickly. While doing that, she answers a question of the other girl in the same activity. When she finishes, she checks on the back to see if she the wrapping was done correctly. She then writes down " +3 " on the "plus" column on her paper. Places the " +3 " back in the jar and looks for another one; picks " -3 ". She thinks for a bit longer before wrapping the tread for each number. Finishes in less than two minutes, checks for the correct pattern on the back of the "wrap-up" and writes down "-3" on the "minus" column on her paper. She puts it back in the jar and picks " +4 ". She looks concentrated on the task and wraps a bit faster this time. When finished, she checks on the back. It is correct. She unwraps the thread and wraps it again neatly for the next child to use it. She puts it back in the 
jar, writes down " +4 " in the "plus" column and picks " -2 ". Two boys next to her make a lot of noise but she is not distracted.

(d) Christina is still working on the "wrap-ups". She has completed all from $-5, \ldots,-1$, and from $+1, \ldots,+5$. She is now working silently with a " +6 ". Momentarily, she makes a puzzled gesture on her face. She then unwraps the thread and starts over again. She is now slower before making a wrap. She stops, looks up and then continues. With three numbers she is whispering, counting numbers upwards and shaking her head at every number. After finishing, she unwraps it and talks to the other girl whether it is time to stop. She looks at the teacher at the other side of the classroom and then wraps it up neatly, puts it back in the jar and writes down " +6 " on her paper. Checks at the "wrap-ups" in the jar to get a new one, uttering their numbers $(+3,-2$, etc.). She picks up " 6 " and starts wrapping it. She is relatively slow again, occasionally closing her eyes, moving her head rhythmically, counting downwards with a whisper. After two minutes she finishes, checks to see if it is correct, she smiles, moves her head positively and writes "-6" down. Puts the "wrap-up" back and prepares her paper before handing it to the teacher. Writes her name on and walks towards the teacher. On the way she stops and talks to another girl. She then talks to the teacher showing her paper sheet. She smiles and seems satisfied. She returns to her desk.

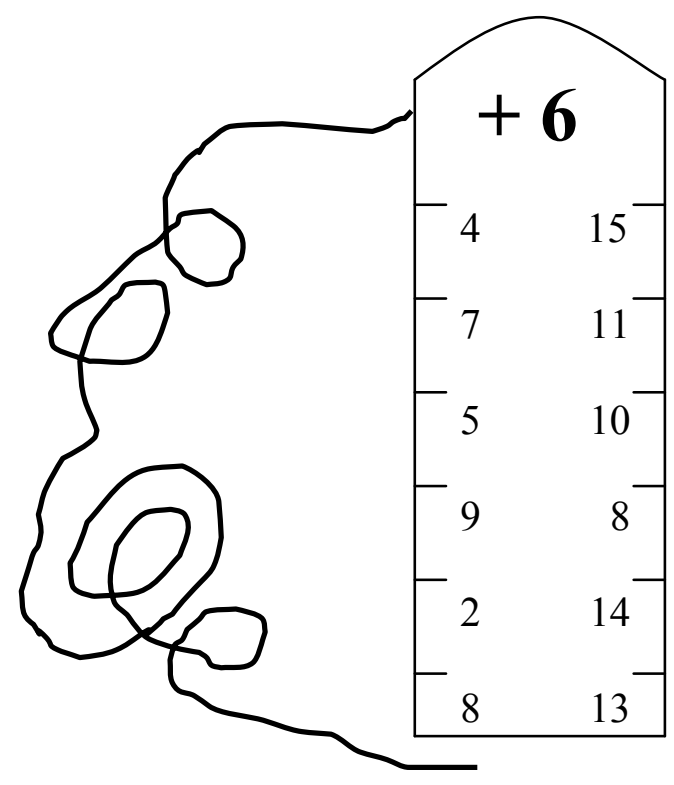

Figure 2. A sketch of a "+6 wrap-up"

Instruction: Starting from the first number on the top left corner the child must match each number on the left side with a number on the right side such that the latter constitutes the sum of the number on the left plus six. On the back of the "wrap-up" there is a line, which coincides with the correct way the thread should be wrapped. 


\section{Comments and analysis of Christina's observation}

In contrast to Marc, Christina follows instructions immediately, as soon as the teacher says something. In general, she could be characterized as an obedient student that does not cause trouble in the classroom and behaves as the teacher expects her to behave. Of course this is not meant to be interpreted in absolute terms, since the classroom environment is not at all in constant order; it is rather informal. She did not pay attention continuously, but often exchanged a chat with other girls or indicated that she was not very excited by the ongoing activities. Soon though, she turned her attention back to the teacher or her task.

She was also organized in her actions. Before starting an activity for example, she first prepared the paper where she was going to record her answers. Similarly, in the individual activity of the "wrap-ups" she was systematic in the procedures she followed. She knew which numbers she was supposed to do, how to "wrap them up", how to check and record them, and how to return the objects back to their place ready for the next user. In fact, she went through these routines 12 times but did not seem to be particularly bored. On the contrary, she seemed to be satisfied with her accomplishments.

When wrapping for small numbers, either for addition, or for subtraction, she was quite fast. There was no indication of how she might have been thinking when doing that; probably operations with small numbers were done automatically, or if she was counting upwards or backwards in her mind, she was doing it fluently. For larger numbers, like six though, she was less quick. She stopped to think before any wrapping. Her whispers and rhythmic movement of head indicated that she was using a counting strategy. She took the first number and counted for example six more numbers to find the sum of that number with six.

\section{Conclusions and Further Questions}

The main question, which guided this exploratory study was how two children behaving in quite different ways in the classroom approached individual and whole class tasks. Indeed, the two children exhibited different patterns of participation and work. From their behavioral samples, the children seemed able to carry out most of the tasks they were assigned to, as well as participate in on-going classroom discussions. However, each one of 
them displayed different characteristics. For example, Marc was reluctant to follow instructions, even when all his classmates did, and occasionally caused trouble and annoyance. He was often distracted, but was able to follow most of the activities that went on in the classroom and participate to some extent. Christina, on the other hand conformed with what the teacher said and was more willing to carry out the tasks that were assigned to her. Occasionally she was distracted as well. An interesting question is of course whether these differences, which are not unique in this particular elementary school classroom, are related to gender.

Although the focus of the observations was on individual children, some concluding comments on the classroom context should be made, because unambiguously the context influences the behavior of the individuals. The teacher used to give specific instructions before allowing children move to an activity. As a result, too much fuss was avoided. Additionally, the children, as was in many instances noticed during the observations, were generally knowledgeable of what to do in each activity, where to look for necessary materials and whom to ask for help. Knowing how to behave at different times and having some routines during the classroom time and familiarity with the activities helped children anticipate what might happen (although surprises were not rare for them), know what to do in each occasion, have a specific goal in mind and anticipate certain outcomes. Moreover, the flexibility and ease with which the children seemed to act should be linked to the informal structure of the classroom. The teacher for example was seen to answer the telephone, or check her email, children often sat on the floor, or moved around in the class and changed places too often. Finally, it should be mentioned that laborious activities in mathematics like practicing addition and subtraction were exciting for the children, due to the originality and richness of activities, the flexibility and change between topics and places, the variety of means and visual stimuli used and the pleasant and caring personality of the teacher.

Another issue that pertains to the differential behavior, cognitive and social, in a classroom, but did not emerge from the observations is the broader cooperative framework of classroom learning. Because the observational sessions touched individual tasks and whole class instruction only, it was not possible to examine how the children would behave in collaborative activities. It is anticipated that under such conditions the children would probably demonstrate different behavioral patterns. An alternative explanation that could be given, but cannot be verified from the existing observations, is that collaborative activities are not planned very often in the particular classroom. Maybe the teacher assumes that second grad- 
ers are not old enough to spend significant amount of time working together. Therefore, even though they are grouped to certain activities and "corners", they typically deal with the tasks individually. Cognitive and social behavior and strategies in collaborative environments are interesting questions that call for further investigation.

For the second goal of studying features of mental strategies, observational techniques by themselves are not adequate, especially when observing individuals in group settings. Some insights were possible when the two children worked on tasks individually. First, it was the input of non-verbal behavior, which can contribute to understanding thinking processes. Second, it was the thinking aloud strategies, either in the form of monologue as Christina sometimes did, or in the form of discussion with oneself, as Marc did. What can be said about these strategies is that expressing thoughts loudly is a strategy that children - and older people - employ more often in difficult and complex tasks, rather than easy ones that are executed automatically. It is also possible that it is an effective way of detecting flaws and errors in the thinking process. However, a more systematic study of the features, as well as the content of mental strategies would be much more fruitful and perceptive if observations are combined with interviewing and written and task-based assessments.

\section{References}

Cohen, L., Manion, L., \& Morrison, K. (2000). Research Methods in Education (5th edition). London: Routledge Falmer.

Neuman, W. L. (2006). Social Research Methods (6th edition). Boston, MA: Pearson Education Inc.

Wright, H. F. (1960). Observational Child Study. In P. H. Mussen (Ed.), Handbook of Research Methods in Child Development, (pp.71-139). New York: John Wiley \& Sons, Inc. 